\title{
Kesim artıklarının kızılçam fidecik özelliklerine etkisi
}

\section{Effects of harvesting residues on juvenile seedling characteristics of brutian pine}

\author{
Durmuş ÇETINKAYA ${ }^{1}$ (Debi Bílí ${ }^{2}$ \\ ${ }^{1}$ Çukurova Üniversitesi, Aladağ Meslek Yüksekokulu, Aladağ, Adana \\ ${ }^{2}$ Isparta Uygulamalı Bilimler Üniversitesi, Orman Fakültesi, Orman Mühendisliği Bölümü, Isparta
}

Eser Bilgisi / Article Info

Araştırma makalesi / Research article

DOI: 10.17474/artvinofd.717040

Sorumlu yazar / Corresponding author

Durmuş ÇETINKAYA

e-mail: durmuscetinkaya@gmail.com

Geliș tarihi / Received

09.04.2020

Düzeltme tarihi / Received in revised form

22.05.2020

Kabul Tarihi / Accepted

28.05.2020

Elektronik erişim / Online available

26.08.2020

Anahtar kelimeler:

Fidecik

Fidanlık

Tohum

Hipokotil

Kotiledon

\section{Keywords:}

Juvenile seedling

Nursery

Seed

Hypocotyl

Cotyledon

\begin{abstract}
Özet
Kızılçam (Pinus brutia Ten.) fidecik özellikleri üzerinde gerçekleştirilen bu çalışmada, fidanlık koşullarında ekim yastıklarına kesim artıkları (ibre, dal ve kabuk) uygulanarak türün tohum meşceresi ve tohum bahçesi orijinlerinden yetiştirilen fideciklerinde; fidecik boyu, hipokotil boyu, epikotil boyu ve kotiledon sayısı araştırılmıştır. Tohum kaynağı ve işlemler arasında geniş farklııklar bulunmakla birlikte çalışma sonucunda; ortalama fidecik boyu $8.03 \mathrm{~cm}$, ortalama hipokotil boyu $1.33 \mathrm{~cm}$, ortalama epikotil boyu $6.70 \mathrm{~cm}$ ve ortalama kotiledon sayısı 7.98 bulunmuştur. Uygulanan varyans analizi sonucunda, epikotil boyu dışındaki diğer fidecik özellikleri için tohum kaynakları ve işlemler arasında istatistiksel bakımından anlamlı farklılık $(p<0.05)$ ortaya çıkmıştır. Uygulanan korelasyon analizi sonucunda, fidecik özellikleri arasında istatistiksel bakımdan anlamlı $(p<0.05)$ pozitif ilişkiler bulunmuştur. Fidecik boyu bakımından her iki tohum kaynağında da dal işlemlerinin diğer işlemlere oranla daha başarılı olduğu söylenebilir.
\end{abstract}

\begin{abstract}
Height, hypocotyl length, epicotyl length and cotyledon number were investigated in juvenile seedlings of its seed orchard and seed stand treated by harvesting residues (neddle, branch and bark) of Brutian Pine (Pinus brutia Ten.). Averages of height, hypocotyl length, epicotyl length and cotyledon number in juvenile seedlings were $8.03 \mathrm{~cm}, 1.33 \mathrm{~cm}, 6.70 \mathrm{~cm}$ and 8 , respectively, while there were large differences between seed sources and among treatments. Results of analysis of variance showed statistically significant $(p<0.05)$ differences between seed sources and among treatments for the characteristics except for epicotyl length. Positive and significant $(p<0.05)$ relations were generally found among the characteristics based on the results of correlation analysis. Branch treatment showed higher growth performance for seedling height than other treatments in both seed sources.
\end{abstract}

\section{Giriş}

Gerek ülkemizde ve gerekse diğer ülkelerde artan nüfusa paralel olarak orman ve orman ürünlerine olan talepte çeşitlenerek artmaktadır. Buna karşın, 21.7 milyon hektar Türkiye ormanlarının, \%46.7'lik kısımı verimsiz yani kendinden beklenen faydayı sağlayamamaktadır (Anonim 2015). Bu orman alanları içinde doğal çam türlerinden olan Kızılçam (Pinus brutia Ten.) 5.854 .673 hektarlık yayılışı ile önemli bir paya ve hatta ülkemizde en geniş doğal yayılışa sahip olup mevcut Kızılçam ormanlarının \%45.2'si, bozuk orman niteliğindedir (Anonim 2015) ve verimli hale dönüştürülmeyi beklemektedir, diğer bir ifadeyle ağaçlandırmaya konu alanlardır. Türün bu geniş yayııış alanı ağaçlandırma çalışmalarındaki geniş kullanım potansiyeli ve dolayısıyla kaliteli fidan üretiminin önemi ile gençleştirme, bakım gibi ormancılık uygulamaları sonucu ortaya çıkacak kesim artığı potansiyelini de açıkça göstermektedir.

Orman ürünlerine olan talep ile çeşitliliğinin karşılanmasında ve verimsiz ormanların ıslahı mevcut ormanlar ile orman ürünlerinden yararlanmayı da ön plana çıkarmaktadır. Bu ürünlerden biri de mevcut itibari ile beklenen seviyede değerlendirilemeyen ve ormancılık uygulamaları sonucunda ormanda kendi haline bırakılan 
kesim artıklarıdır. Bu bağlamda, ülkemizde de israfın önlenmesini, kaynakların daha verimli kullanılmasını, atık oluşum sebeplerinin gözden geçirilerek atık oluşumunun engellenmesi veya minimize edilmesi, atığın oluşması durumunda ise kaynağında ayrı toplanması ve geri kazanımının sağlanmasını kapsayan atık yönetim felsefesi olarak tanımlanan bir hedef olarak adlandırılan SIFIR ATIK projesi başlatılmış ve Sıfır Atık Yönetmeliği 12.07.2019 tarih ve 30829 nolu resmî gazetede yayımlanmıştır. Miktar bakımından önemli potansiyele sahip ve ülkemizde henüz beklenen seviyede değerlendirilemeyen kesim artıkları, bir ağacın ana gövdesi dışında kalan ve 0.6 $\mathrm{cm}$ ye kadar olan bütün ince dallar, kabuk, sürgünler, yapraklar, kozalaklar, meyveler, ibreler ve çiçekleri olarak tanımlanmaktadır (Alma ve Çetin 2002, Vurdu 1983) ve bu kaynaklar mevcut itibariyle sınırlı seviyede kullanılmaktadır.

Ancak bu artıklar birçok ürün için hammadde ihtiyacını karşılamada önemli bir kaynak olarak; enerji üretimi, hayvan yemi veya katkısı, gübre olarak kullanımı ve kimya endüstrisi, kâğıt ve levha üretimi, kozmetik sanayii gibi çeşitli kullanım alanları bilinmektedir. Foliage olarak da bilinen orman kesim artıklarının miktarı, başta ağaç türü olmak üzere, ağaç yaşı, boyu, göğüs yüksekliği çapı, bonitet, kesim zamanı, tepe çapı ve tepe boyu gibi pek çok değişkene bağlı olarak farklııı göstermektedir (Ateş ve ark. 2007).

Ormanda bakım ve hasat kesimleri sırasında faydalanılabilir ebat ve niteliklerdeki ürünler çıkarıldıktan sonra sahada fazla miktarda "düşük nitelikli" kesim artığı kalmaktadır. Bunlar arasında orta-kalın çaplı dal parçaları, ince uç sürgünler ve yapraklar, kozalak, kabuk ve faydalanılamayan gövde kısımları sayılabilir. Sahada terk edilen bu kesim artıkları, orman tabanında biriken ölü örtüye karışmakta ve bu organik artıkların zamanla ayrışması ile yapılarında bulunan besinler ayrışarak inorganik hale geçmekte ve ağaçların besin kaynaklarından birisini oluşturmaktadırlar (Özel 2014). Her yıl dökülen yaprakların bir kısmı orman tabanında birikmekte ve ormanda biriken ölü örtü miktarı; ormanın yaşına, türüne, verim gücüne ve bulunduğu ortama göre değişim göstermektedir. Örneğin, saf kızılçam ormanlarında kötü bonitetlerde hektarda yaklaşık 20 ton ölü örtü bulunurken verimli sahalarda bu değer 40 tona kadar çıkmaktadır (Eker ve ark. 2013). Koparan (2015) ağaç kabuğunun önemli bir organik ve yenilenebilir hammadde olduğunu ve peyzaj ile diğer amaçlarda kullanım potansiyeli olduğunu belirttikleri çalışmalarında 81 yaşındaki Kızılçamda kabuk miktarı 923 kg, 174 yaşındaki Karaçam'da ise $997 \mathrm{~kg}$ olarak bulmuş ve bu miktardaki kabuğun Kızılçamda $105 \mathrm{~m}^{2}$, Karacamda ise $150 \mathrm{~m}^{2}$ lik alanı örttüğünü belirlemiştir. Kantarcı (2000), kesim artıklarının zamanla ayrışarak bitkilerin beslenmesi ve büyümesi için oldukça önem taşıdığını ifade etmektedir. Karayılmazlar ve ark. (2011) ise orman ağacı artıkları ile oluşan ölü örtünün tohumların çimlenmesini kolaylaştırdığı ve böylece gençleştirme çalışmalarına olumlu katkı sağladığını belirtmektedirler. Çetinkaya ve Bilir (2017) yapmış oldukları çalışmada, odun üretimi sonrasında değerlendirilmeyen kızılçam kabuğunun yedi orman ağacı türü (Pinus sylvestris L., $P$. nigra Arnold., $P$. brutia Ten., P. pinaster Ait., Thuja orientalis L., Gleditsia triacanthos L., Robinia pseudoacacia L.) tohumunda çimlenmeye olan etkisini araştırmışlar ve çalışma sonucunda kabuklardan elde edilen sıvının, türlerin çimlenme performanslarını (çimlenme değeri, çimlenme yüzdesi ve çimlenme süresi) olumlu etkilediğini belirleyerek sonuçları tür bazında değerlendirilmişler ve kesim artıklarının ormancılıkta değişik amaçlara hizmet edebildiği ve ekonomik değer potansiyeline sahip olabileceğini ifade etmişlerdir.

Gerek yukarıda verilen değerler ve gerekse türün ülkemizdeki geniş doğal yayılışı ile odun hammaddesi üretimindeki önemi türün kesim artığı potansiyeli ile ekonomikliğini de açıkça vurgulamaktadır. Bu bağlamda çalışmada; Kızılçam kesim artıklarının organik gübre olarak ülke ekonomisine kazandırılma potansiyelinin belirlenmesi; türün fidanlık tekniği ile diğer ormancılık uygulamalarına katkı sağlanması amaçlanmıştır.

\section{MATERYAL VE YÖNTEM}

\section{Materyal}

Çalışma, Adana Orman Bölge Müdürlüğü'ne bağlı olarak 1964 yılında tesis edilen Pos-Kıcak Orman Fidanlığında gerçekleştirilmiştir. Fidanlık, $35^{\circ} 12^{\prime} 45^{\prime \prime}$ doğu boylamı ile 
$37^{\circ} 34^{\prime} 40^{\prime \prime}$ kuzey enlemlerinde ve 980 metre yükseltide yer almaktadır.

Çalışmada materyal olarak, Pos-Kıcak Orman Fidanlığından sağlanan Adana-Pos bölgesinde tescil edilen 2 nolu Karsantı tohum meşceresine (TM, 37 ${ }^{\circ} 34^{\prime} 30^{\prime \prime}$ doğu boylamı, 35²4'30" kuzey enlemi, 745 metre yükselti) ve Adana-Ceyhan bölgesinde 1986 yılında tesis edilen 26 nolu Cehennemdere Kızılçam tohum bahçesine (TB, 3706'55" doğu boylamı, 3548'30" kuzey enlemi, 30 metre yükselti) ait tohumlardan yöntem bölümünde detaylandırılan usuller eşliğinde üretilen fidecik materyali kullanılmıştır.
Çalışmada Kızılçamın 2017 yılında Adana-Pos yöresi doğal gençleştirme sonucu sahada bırakılmış dal (D), kabuk (K) ve ibrelerine (i) ait kesim artıkları $0.6 \mathrm{~mm}$ boyutunda öğütülerek ekim öncesi kullanıma hazır hale getirilmiş ve kapalı ortamda ağzı açık halde polietilen kaplarda ekim zamanına kadar hava kurusu ortamda muhafaza edilmiştir ve Nisan-2018 döneminde ekim yastıklarına 500 $\mathrm{g} / \mathrm{m}^{2}$ olacak şekilde uygulanarak ekim işlemi üç tekrarlı olarak kontrol işlemiyle birlikte (Ko) gerçekleştirilmiştir (Şekil 1).

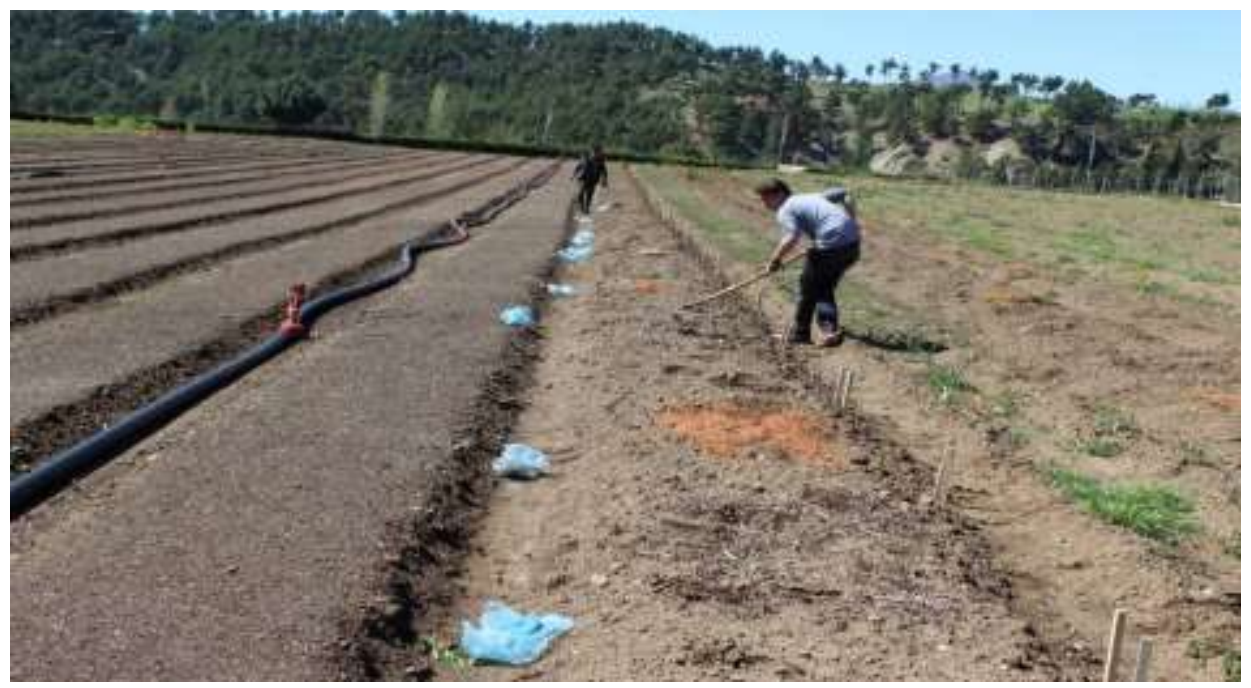

Şekil 1. Ekim yastığı hazırlığı ve kesim artıkları ile muamelesi

Çimlenme aşamasının tamamlanması sonrası ve fideciklerin odunlaşmaya başlamasıyla her işlemden rastgele örneklenen $15^{\prime}$ er adet fidecikte aşağıdaki fidecik özelliklerinin ölçümü gerçekleştirilmiştir:

Hipokotil boyu (HB): Kök boğazından kotiledonlara kadar olan kısım olup, cetvel yardımıyla $1 \mathrm{~mm}$ hassasiyette;

Epikotil boyu (EB): Kotiledonlardan fidecik tepesine kadar olan kısım olup, cetvel yardımıyla $1 \mathrm{~mm}$ hassasiyette;

Fidecik boyu (FB): Kök boğazından fidecik tepesine kadar olan kısım olup, cetvel yardımıyla $1 \mathrm{~mm}$ hassasiyette;

Kotiledon sayısı (KS): Fideciklerdeki kotiledonların sayısı ölçülmüştür.
Elde edilen veriler SPSS paket programında değerlendirilerek temel istatistiksel değerler yanında, çalışmaya konu özellikler bakımından tohum kaynağı ve işlemler arası karşılaştırmalar, aşağıdaki çoklu varyans analizi (MANOVA) modeli yardımıyla gerçekleştirilmiştir:

$$
Y_{i_{j}}=\mu+P_{i}+S_{j}+P(S)_{i(j)}+e_{i j k}
$$

Burada $Y_{i j k}, i$ işlemin $j$. tohum kaynağındaki $k$. fideciğe ait değeri; $\mu$, genel ortalamayı; $\mathrm{P}_{i, j}$. Tohum kaynağının $i$. işlemdeki etkisini; $\mathrm{P}(\mathrm{S})_{i(j)}$ tohum kaynağı ile işlem etkileşimini; $e_{i j k}$ ise hatayı göstermektedir.

Bunlara ek olarak özellikler arasındaki ilişkiler korelasyon analizi ile bulunmuştur. 


\section{BULGULAR VE TARTIŞMA}

\section{Fidecik Özellikleri}

Fideciklerde ortalama fidecik boyu $8.03 \mathrm{~cm}$ bulunmuş olup bu değer işlemlerde $6.99 \mathrm{~cm}$ (TB-K) ile $8.66 \mathrm{~cm}$ (TMD) arasında değişim göstermiştir ve genel olarak tohum meşceresi orijinli fideciklerin $(8.32 \mathrm{~cm})$ tohum bahçesi orijinli fideciklere $(7.74 \mathrm{~cm})$ göre daha yüksek fidecik boyu gelişimi yaptığı belirlenmiş ve kontrol işlemleri her iki tohum kaynağında da en düşük fidecik boyu gelişimi göstermiştir (Çizelge 1, Şekil 2). Kızılçam üzerinde gerçekleştirilen bir çalışmada elde edilen $10.22 \mathrm{~cm}$ 'lik fidecik boyu (Çalışkan 2006), çalışmamız sonucu elde edilen fidecik boyuna oranla nispeten daha yüksektir.
Fidecik boyu bakımından her iki tohum kaynağında da dal işleminin diğer işlemlere oranla daha başarılı olduğu söylenebilir.

Elde edilen veriler ışığında ortalama hipokotil boyu 1.33 $\mathrm{cm}$ bulunmuş olup bu değer işlemlerde 1.03 (TB-D) ile $2.09 \mathrm{~cm}$ (TM-D) arasında değişim göstermiştir (Çizelge 1). Ortalama değerler ele alındığında hipokotil boyu bakımından tohum meşceresi dal işleminin (TM-D) diğer işlemlere göre daha başarılı olduğu ve hipokotil boyu bakımından tohum meşceresi tohum kaynağına uygulanan işlemlerin tamamının tohum bahçesi tohum kaynağına oranla daha yüksek hipokotil boyu gelişimi gösterdiği belirlenmiştir (Çizelge 1, Şekil 2)

Çizelge 1. İşlem ve tohum kaynaklarına göre fidecik özelliklerine ilişkin ortalama değerleri

\begin{tabular}{|c|c|c|c|c|}
\hline \multirow[t]{2}{*}{ Tohum kaynağı-İşlem } & \multicolumn{4}{|c|}{ Fidecik özellikleri } \\
\hline & $\mathrm{FB}(\mathrm{cm})$ & $\mathrm{HB}(\mathrm{cm})$ & EB (cm) & KS \\
\hline TM-K & $8.31 b c^{*}$ & $1.53 c$ & 6.78 & $8.73 c$ \\
\hline TM-i & $8.43 c$ & $1.49 c$ & 6.94 & $8.67 c$ \\
\hline TM-Ko & $7.91 \mathrm{abc}$ & $1.42 \mathrm{bc}$ & 6.49 & 7.33ab \\
\hline TM-D & $8.66 c$ & $2.09 d$ & 6.57 & $8.53 b c$ \\
\hline TB-K & $6.99 a$ & $0.97 a$ & 6.03 & $8.27 b c$ \\
\hline TB-i & $8.05 b c$ & $1.11 \mathrm{ab}$ & 6.93 & $6.93 a$ \\
\hline TB-Ko & 7.38ab & $1.06 a$ & 6.32 & $7.47 a b c$ \\
\hline TB-D & $8.55 c$ & $1.03 a$ & 7.51 & $7.93 a b c$ \\
\hline Genel & 8.03 & 1.34 & 6.70 & 7.98 \\
\hline
\end{tabular}

*; Aynı harfler benzer grupları göstermektedir.

Uygulanan varyans analizi sonucunda tohum kaynakları ve işlemler arasında fidecik boyu, hipokotil boyu ve kotiledon sayısı bakımından anlamlı farklılık $(p<0.05)$ ortaya çıkmıştır. Duncan testi sonucunda, her iki tohum kaynağında da işlemler, fidecik boyu, hipokotil boyu ve kotiledon sayısı bakımından üçer homojen grup oluşturmuştur (Çizelge 1).

$\mathrm{Bu}$ sonuç fidanlık uygulamalarında kesim artıklarının kullanılabilme potansiyelini de göstermektedir. Benzer şekilde, Çetinkaya ve Bilir (2017) gerçekleştirmiş oldukları çalışmada, odun üretimi sonrasında değerlendirilmeyen Kızılçam kabuğunun yedi orman ağacı türü tohumunda çimlenme performanslarını olumlu etkilediğini belirleyerek sonuçları tür bazında değerlendirmişlerdir. Ancak gerçekleştirilen bu çalışmamızda sadece bir doz $\left(500 \mathrm{~g} / \mathrm{m}^{2}\right)$ uygulama yapılmış ve kesim artıklarının kombinasyonları ve farklı dozları denenmemiş olup uygulama sonrası çalışma sonuçlarına ilişkin veriler kısa süre sonrasında elde edilmiştir. Buna karşın Kantarcı (2000), kesim artıklarının zamanla ayrışarak bitkilerin beslenmesi ve büyümesi için oldukça önem taşıdığını ifade etmektedir.

Tohum kaynağı ve işlemlere bakılmaksızın ortalama epikotil boyu $6.70 \mathrm{~cm}$ bulunurken bu değer orijin ve işlemler arasında $6.03 \mathrm{~cm}$ (TB-K) ile $7.51 \mathrm{~cm}$ (TB-D) arasında değişmektedir (Çizelge 1, Şekil 2). 


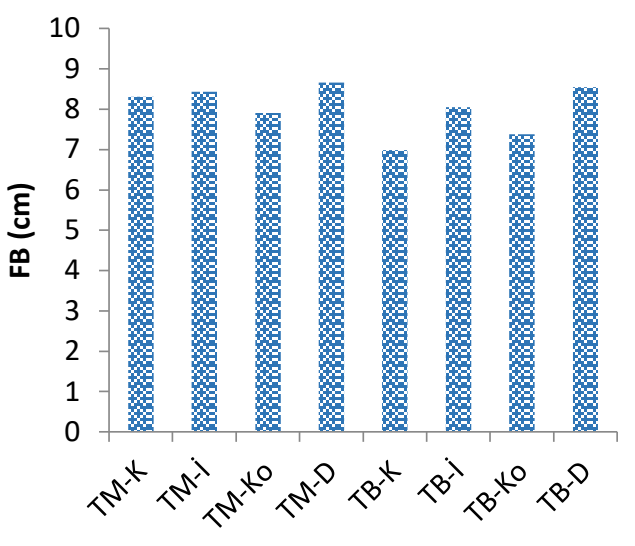

Tohum kaynağı ve işlemler

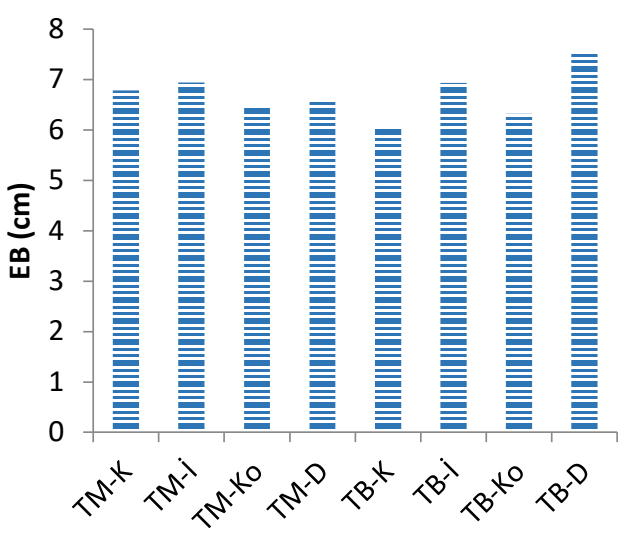

Tohum kaynağı ve işlemler

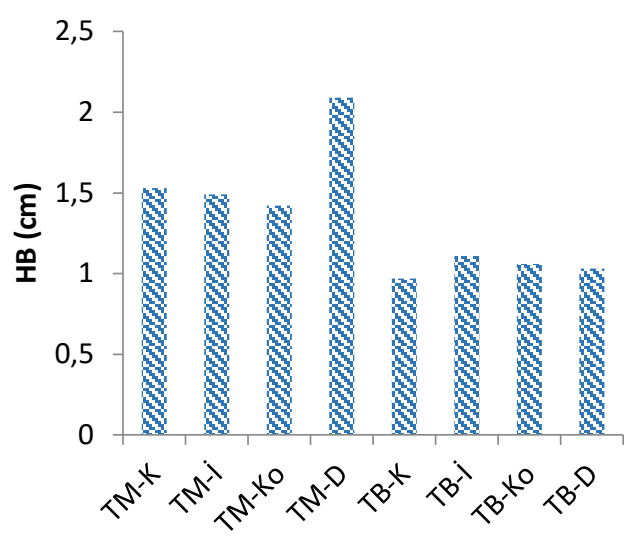

Tohum kaynağı ve işlemler

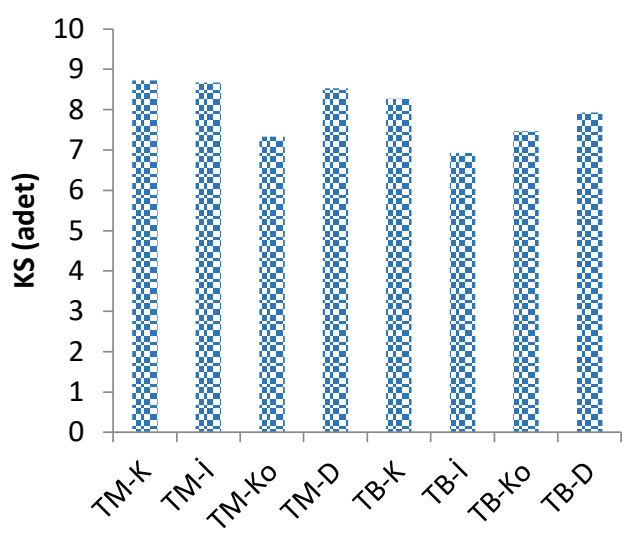

Tohum kaynağı ve işlemler

Şekil 2. İşlem ve tohum kaynaklarına göre ortalama fidecik özellikleri

Fraxinus angustifolia Vahl. fidecikleri üzerinde yapılan çalışmada epikotil boyunun genetiksel bakımdan önemli bir fidecik özelliği olduğu (Çiçek ve ark. 2009); Pinus radiata D.Don fidanlarının performanslarının incelendiği çalışmada ise epikotil boyunun tohum kaynaklarına göre son derece belirleyici bir özellik olduğu ifade edilmiştir (Hargreaves ve ark. 2005).

Ortalama kotiledon sayısı bakımından tohum meşceresinden yetiştirilen fideciklerin (8.31) tohum bahçesi fideciklerine (7.65) göre daha fazla kotiledona sahip oldukları görülmüştür (Çizelge 1 , Şekil 2). Tohum kaynağı ve işlemlere bakılmaksızın ortalama kotiledona sayısı 7.98 bulunmuştur. Bu sonuçlara benzer olarak Yücedağ ve Gezer (2014) dört kızılçam tohum meşceresinden sağlanan tohumlardan elde ettikleri fideciklerde ortalama kotiledon sayısını 7.70 olarak tespit etmişlerdir. Nitekim, kızılçam orijinlerinde kotiledon sayısının 4 ile 12 arasında değiştiği de belirtilmektedir (Yahyaoğlu 1983). Kotiledon sayısı, sulama, gübreleme, fidanlık tekniği vb. çevresel faktörlerden etkilenme düşüklüğü bakımından genetik çeşitliliğin göstergesi olabilecek önemli fidecik özelliklerinden biridir.

Tohum kaynağı ve işlemleri çalışmaya konu özellikler bakımından karşılaştırılması amacıyla uygulanan varyans analizi sonucunda epikotil boyu için tohum kaynağı ve işlemler arasında istatistiksel bakımdan anlamlı fark olmadığı ( $p>0.05)$ belirlenirken; diğer özellikler için tohum kaynağı ve işlemler arasında istatistiksel bakımdan anlamlı $(p<0.05)$ farklılık olduğu ortaya çıkmıştır.

\section{Fidecik Özellikleri Arasındaki iliş̧kiler}

Tohum kaynağı ve işlemlere bakılmaksızın, çalışmaya konu fidecik özellikleri arasındaki ilişkileri belirlemek 
amacıyla uygulanan korelasyon analizi sonucunda fidecik boyu ile hipokotil boyu arasında ( $r=0.359$ ); fidecik boyu ile epikotil boyu arasında ( $r=0.906)$; kotiledon sayısı ile hipokotil boyu arasında $(r=0.216)$ istatistiksel bakımdan anlamlı $(p<0.05)$ pozitif ilişkiler olduğu ortaya çıkmıştır (Çizelge 2). Bu sonuçlara benzer olarak Yahyaoğlu (1983) tarafından Kızılçam orijinleri üzerinde gerçekleştirilen bir çalışmada da kotiledon sayısı ile fidecik boyu ve hipokotil uzunluğu arasında güçlü ilişkiler olduğu ortaya çıkarılmıştır. Benzer sonuçlar Bilgin (2008) tarafından Fıstıkçamı (Pinus pinea L.) fideciklerinde de elde edilmiştir. Sarıçam üzerinde gerçekleştirilen bir çalışmada kotiledon sayısı ve fidan boyu arasında doğrusal bir ilişki olduğu ifade edilmiştir (Ulusan ve Bilir 2008). Bu sonuçlara benzer olarak, Karaçamda (Pinus nigra Arnold.) yapılan çalışmada kotiledon sayısının artmasıyla fideciklerin daha hızlı kök gelişimi performansı sergilediği gözlenmiştir (Çılgın ve ark. 2007). Ancak, ilginç bir şekilde kotiledon sayısı ile epikotil boyu arasında anlamlı bir ilişki bulunmamıştır (Çizelge 2). Bu çalışmada kotiedon sayısı ile epikotil boyu arasında ilişki bulunmamasına rağmen, Yahyaoğlu (1983), Yücedağ ve Gezer (2014) tarafından pozitif yönde anlamlı bir ilişki tespit edilmiştir.

Çizelge 2. Fidecik özellikleri arasındaki ilişkiler

\begin{tabular}{llll}
\hline$r$ & $\mathrm{FB}$ & $\mathrm{HB}$ & $\mathrm{EB}$ \\
\hline $\mathrm{HB}$ & $.359^{* *}$ & - & \\
\hline $\mathrm{EB}$ & $.906^{* *}$ & $-.071^{\mathrm{NS}}$ & - \\
\hline $\mathrm{KS}$ & $.166^{\mathrm{NS}}$ & $.216^{*}$ & $.079^{\mathrm{NS}}$
\end{tabular}

**; ilişkiler $p<0.01$ ve *; ilişkiler $p<0.05$ seviyesinde anlamlı, NS; ilişkiler anlamsızdır ( $p>0.05)$.

\section{SONUÇLAR}

Tohum kaynağı ve işlemlerde ortalama fidecik boyu 8.03 $\mathrm{cm}$, hipokotil boyu 1.33 epikotil boyu $6.70 \mathrm{~cm}$, kotiledon sayısı ise 7.98 bulunmuştur. Bu özellikler tohum meşceresi fideciklerinde sırasıyla $8.33 \mathrm{~cm}, 1.63 \mathrm{~cm}, 6.70$ $\mathrm{cm}$ ve 8.32 adet bulunurken tohum bahçesi fideciklerinde $7.74 \mathrm{~cm}, 1.04 \mathrm{~cm}, 6.70 \mathrm{~cm}$ ve 7.65 adet bulunmuştur. Bu sonuç, tohum meşceresi fideciklerinin tohum bahçesi fideciklerine oranla daha fazla gelişim gösterdiğini ortaya çıkarmıştır. Ancak, bu gelişim performansı farklılığı çalışmanın fidan, ağaçlandırma gibi ileriki aşamalarında değişim gösterebilir. Bununla birlikte, tohum bahçesi fideciklerinin büyüme performansı düşüklüğü tohum bahçesi $(30 \mathrm{~m})$ ile fidanlık $(980 \mathrm{~m})$ arasındaki geniş yükselti farklılığından kaynaklandığı tahmin edilmektedir. Bu sonuç tohum kaynağı ve fidanlık konumunun önemini bir kez daha vurgulamaktadır.

Tohum kaynakları ve işlemler arasında fidecik boyu, hipokotil boyu ve kotiledon sayısı bakımından anlamlı farklıık ( $p<0.05$ ) ortaya çıkarken; epikotil boyu için tohum kaynağı ve işlemler arasında istatistiksel bakımdan anlamlı fark olmadığı ( $p>0.05)$ belirlenmiştir. Bu sonuçlar fidanlık uygulamalarında kesim artıklarının kullanılabilme potansiyelini ve fidecik gelişimine olumsuz bir etkisinin olmadığını göstermektedir. Ancak, çalışmamızda sadece bir doz $\left(500 \mathrm{~g} / \mathrm{m}^{2}\right)$ ve tek dönem kesim artığı uygulaması yapılmış ve kesim artıklarının kombinasyonları ve farklı dozları denenmemiştir ve ileriki çalışmalarda farklı miktarda kesim artıkları ve bunların kombinasyonları ile farklı dönem uygulamalarının denenmesi kesim artıklarının fidanlık uygulamalarında kullanılabilirliğini daha belirgin bir şekilde ortaya çıkarabilir.

Çalışmaya konu fidecik özellikleri arasındaki ilişkileri belirlemek amacıyla uygulanan korelasyon analizi sonucunda genel olarak çalışmaya konu fidecik özellikleri arasında istatistiksel bakımda anlamlı $(p<0.05)$ pozitif ilişkiler olduğu ortaya çıkmıştır ve bu sonuç ileride yapılacak muhtemel çalışmaların daha az fidecik özellikleri ile de gerçekleştirilebileceğini göstermektedir.

\section{TEŞEKKÜR}

Bu çalışma Prof. Dr. Nebi Bilir danışmanlığında tamamlanan doktora tez çalışmasının bir bölümünü içermektedir. Katkılarından dolayı tez izleme komitesinin sayın üyelerine teşekkür ederiz.

\section{KAYNAKLAR}

Alma MH, Çetin NS (2002) Orman foliagesi üzerinde etkili olan faktörler ve foliagenin kullanım yerleri. II. Ulusal Karadeniz Ormancılık Kongresi, Trabzon, s1049-1056

Anonim (2015) Türkiye orman varlığı 2015. TC. Orman ve Su İşleri Bakanlığı, Orman Genel Müdürlüğü, Ankara

Ateş S, Akyıldız MH, Vurdu H, Akgül M (2007) Türkiye'de orman kesim artıkları ve değerlendirilmesi. Kastamonu Orman Fakültesi Dergisi $7(1): 93-104$

Bilgin S (2008) Fıstıkçamı (Pinus pinea L.)'nın tohum-fidan ilişkileri ve fidanlıkta fidan yetiştirme teknikleri. Süleyman Demirel Üniversitesi Fen Bilimleri Enstitüsü, Doktora Tezi, Isparta, 82s 
Çalışkan S (2006) Doğal Kızılçamlarda (Pinus brutia Ten.) populasyonlararası ve içi genetik çeşitlilik. Journal of the Faculty of Forestry Istanbul University 56 (1):169-196

Çetinkaya D, Bilir N (2017) Kızılçam (Pinus brutia) kabuğunun çimlenme üzerine etkileri. $2^{\text {nd }}$ International Mediterranean Science and Engineering Congress, Adana, pp 480-485

Çılgın Ş, Ayan S, Sıvacıoğlu A, iktüeren Ş (2007) Hanönü (Kastamonu)Günlüburun Karaçam (Pinus nigra Arnold. subsp. pallasiana (Lamb.) Holmboe) tohum bahçesinde bazı klonların kozalak ve tohum özellikleri. Kastamonu University Journal of Forestry Faculty 7 (2):169-179

Çiçek N, Çiçek E, Bilir N (2005) Dar Yapraklı Dişbudak'ta (Fraxinus angustifolia Vahl.) bazı tohum ve fidecik özellikleri. Süleyman Demirel Üniversitesi Orman Fakültesi Dergisi 1:17-24

Eker M, Acar HH, Özçelik R, Alkan H, Gürlevik N, Çoban HO, Korkmaz M, Yılmaztürk A (2013) Ormancılıkta hasat artıklarının tedarik edilebilirliğinin araştırılması. TÜBITAK 1100435 Nolu Proje Sonuç Raporu

Hargreaves CL, Grace LJ, Van der Maas SA, Menzies MI, Kumar S, Holden DG, Foggo MN, Low CB, Dibley MJ (2005) Comparative in vitro and early nursery performance of adventitious shoots from cryopreserved cotyledons and axillary shoots from epicotyls of the same zygotic embryo of control-pollinated Pinus radiata. Canadian Journal of Forest Research 35:2629-2641
Kantarcı D (2000) Toprak ilmi. İstanbul Üniversitesi, Orman Fakültesi Yayını, No:462, İstanbul

Karayılmazlar S, Saraçoğlu N, Çabuk Y, Kurt R (2011) Biyokütlenin Türkiye'de enerji üretiminde değerlendirilmesi. Bartın Orman Fakültesi Dergisi 13:63-75

Koparan i (2015) Kızılçam (Pinus brutia Ten.) ve Karaçam (Pinus nigra subsp. pallasiana) kabuklarının malçlama elemanı olarak kullanım olanakları. Süleyman Demirel Üniversitesi Fen Bilimleri Enstitüsü Yüksek Lisans Tezi, Isparta, 56s

Özel H (2014) Kızılçam ormanında kesim artıklarının ayrışması ve besin döngüsüne katkıları. Süleyman Demirel Üniversitesi Fen Bilimleri Enstitüsü Yüksek Lisans Tezi, Isparta, 81s

Ulusan MD, Bilir N (2008) Broad-sense heritability for seedling characters and its importance for breeding in scots pine. Journal of Science of Suleyman Demirel University 3(2):133-138

Vurdu H (1983) Potential of forest as an animal feed supplement. J. Forest Engineering 20:23-28

Yahyaoğlu Z (1983) Birkaç Pinus brutia Ten. orijininde kotiledon sayısı varyasyonu. K.T.Ü. Orman Fakültesi Dergisi 6(2):407-415

Yücedağ C, Gezer A (2014) Studies on morphogenetic characteristics of juvenile and one year old seedlings of some registered Brutian pine (Pinus brutia Ten.) seed stands in Lakes District. Natural Resources, Green Technology and Sustainable Development, 2628 Kasım 2014, s. 211-216, Zagreb, Hırvatistan 